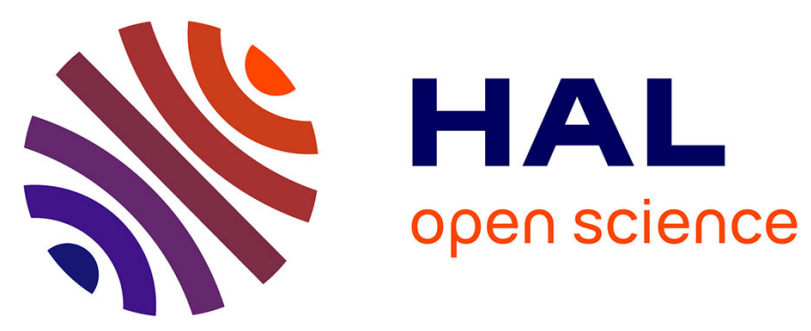

\title{
The role of navigation instruction at intersections for older drivers and those with early Alzheimer's disease
}

Laurence Paire-Ficout, Claude Marin-Lamellet, Sylviane Lafont, Catherine

Thomas-Antérion, Bernard Laurent

\section{- To cite this version:}

Laurence Paire-Ficout, Claude Marin-Lamellet, Sylviane Lafont, Catherine Thomas-Antérion, Bernard Laurent. The role of navigation instruction at intersections for older drivers and those with early Alzheimer's disease. Accident Analysis \& Prevention, 2016, 96, pp.249-254. 10.1016/j.aap.2016.08.013 . hal-01358201v2

\section{HAL Id: hal-01358201 \\ https://hal.science/hal-01358201v2}

Submitted on 11 May 2017

HAL is a multi-disciplinary open access archive for the deposit and dissemination of scientific research documents, whether they are published or not. The documents may come from teaching and research institutions in France or abroad, or from public or private research centers.
L'archive ouverte pluridisciplinaire HAL, est destinée au dépôt et à la diffusion de documents scientifiques de niveau recherche, publiés ou non, émanant des établissements d'enseignement et de recherche français ou étrangers, des laboratoires publics ou privés. 
PAIRE-FICOUT, Laurence, MARIN-LAMELLET, Claude, LAFONT, Sylviane, THOMAS-ANTÉRION, Catherine, LAURENT, Bernard, 2016, The role of navigation instruction at intersections for older driversand those with early Alzheimer's disease, Accident Analysis and Prevention, vol. 96, Elsevier, pp. 249-254, DOI: 10.1016/j.aap.2016.08.013

\section{The role of navigation instruction at intersections for older drivers and those with early Alzheimer's disease}

Laurence PAIRE-FICOUT ${ }^{(1)}$, Claude MARIN-LAMELLET ${ }^{(1)}$, Sylviane LAFONT ${ }^{(2)}$, Catherine THOMAS-ANTÉRION ${ }^{(3)}$, Bernard LAURENT ${ }^{(4)}$

(1) Ifsttar-TS2-Lescot, Bron, France, laurence.paire-ficout@ifsttar.fr, claude.marinlamellet@ifsttar.fr

(2) Ifsttar-TS2-Umrestte, Bron, France, sylviane.lafont@ifsttar.fr

(3) Laboratoire d'Étude des Mécanismes Cognitifs (EMC), EA3082, Université Lyon 2, Bron, France, c.thomas-anterion@orange.fr

(4) Service de neurologie, Hôpital nord, St Etienne, France, bernard.laurent@chu-stetienne.fr

Running head: Aging and Alzheimer's disease at intersections

\section{Contact information:}

Laurence PAIRE-FICOUT

Institut français des sciences et technologies des transports, de l'aménagement et des réseaux (Ifsttar)

Transport Santé Sécurité (TS2)

Laboratoire Ergonomie et Sciences Cognitives pour les Transports (Lescot)

Cité des Mobilités

25, Avenue François Mitterrand

Case 24

69675 Bron Cedex

tel: (33) 472142532

fax: (33) 472146837

email: laurence.paire-ficout@ifsttar.fr 
The role of navigation instruction at intersections for older drivers and those with early Alzheimer's disease

\section{Abstract}

Aims: Our purpose was to explore the effect of navigation instruction on older drivers' driving performance at left turn intersections. Left turns at intersections are particularly complex because they require many perceptive and cognitive abilities under considerable time pressure. Methods: Fifty-four participants were recruited: 18 drivers with early-stage Alzheimer's disease (AD), 18 neurologically healthy older drivers and 18 younger individuals. Various cognitive processes were measured, and 9 left turn maneuvers with or without navigation instruction were evaluated during an in-traffic road test. The psychomotor, planning and decision-making components involved in left turn were also analyzed closely. Results: Only older drivers (both healthy drivers and those with AD) were negatively affected by navigation instruction during the maneuver. The planning and decision-making components were more likely to be affected by the navigation instruction. The Digit Symbol Substitution Test showed the greatest association with the left turn driving scores of older drivers. Conclusion: This finding highlights the importance of carefully considering the use of navigation instructions when developing navigation systems. Adapting this instruction is necessary to simplify our understanding of the real-world driving environment and to avoid increasing the cognitive load of older drivers.

\section{Keywords}

Aging; Alzheimer's disease; Left turn maneuver; Navigation instruction; Cognitive decline 


\section{Introduction}

Research has thoroughly established that a high percentage of older drivers' crashes occur at intersections or in complex driving situations (Preusser et al. 1998, Oxley et al. 2006, Braitman et al. 2007, Clarke et al. 2010, Lafont et al. 2010a). Specific problems arise when drivers turn across traffic (Chandraratna and Stamatiadis 2003, Mayhew et al. 2006, Oxley et al. 2006) or estimate the gaps between their own vehicle and other vehicles (Chandraratna and Stamatiadis 2003, Mayhew et al. 2006). Left turn maneuvers have been identified as one of the most risky driving tasks for older drivers (Chandraratna and Stamatiadis 2003, Mayhew et al. 2006, Gelau et al. 2011) and as the most complex (Staplin et al. 1997, Caird and Hancock 2002). The level of time pressure is generally high in such maneuvers because there may be vehicles both in front of and/or behind the driver: simultaneously, the driver must perceive and interpret roadway situations; develop a plan; use the accelerator, brakes and steering appropriately; and assess the current traffic situation before negotiating the intersection. According to some authors, under normal driving conditions, older drivers are as proficient as younger drivers at driving through intersections. However, when an element of the environment suddenly changes (and was not considered while planning to drive through the intersection), the action of updating one's plan may be more costly for older drivers than for younger drivers (Dukic and Broberg 2012).

The accident risk for older drivers with Alzheimer's disease (AD) has been shown to be higher than that for older drivers without a neurological disease (Friedland et al. 1988, Cooper 1990, Drachman and Swearer 1993, Tuokko et al. 1995, Dubinsky et al. 2000, Dubinsky and Stein 2002). Problematic driving behaviors include incorrect turning (Uc et al. 2005), impaired signaling (Duchek et al. 2003), decreased comprehension of traffic signs (Charlton 2006), lane deviation (Uc et al. 2005) and the tendency to become lost in familiar areas (Uc et al. 2004). Crashes, while infrequent, are also a concern for drivers with dementia, whose crash risk is two to five times that of unimpaired older drivers (Charlton 2006). The most likely reason for this increased risk is that AD drivers, even at an early stage 
of disease, exhibit cognitive and perceptual declines that impair their ability to drive. Speed processing is generally affected in those with AD (Perry and Hodges 1999, Tales et al. 2002, Storandt and Beaudreau 2004, Tales et al. 2004), and patients might also show difficulty preparing for rapidly occurring events and maintaining preparation over time (Sylvain-Roy et al. 2010). This slower processing could delay the time needed to process sensory inputs, to determine safe courses of action, and to implement those actions in a driving context (Rizzo et al. 2001). Some authors have argued that the declining driving performance of those with AD may also result from a decline in selective attention (Duchek et al. 1997, Bieliauskas et al. 1998, Duchek et al. 1998), reduced visuospatial attention (Rizzo et al. 2001, Uc et al. 2004, Grace et al. 2005), or executive dysfunction (Szlyk et al. 2002, Grace et al. 2005, Whelihan et al. 2005, Lafont et al. 2010b).

All of these perceptual and cognitive components are strongly involved in driving activity, particularly in complex situations such as making left turns at intersections. Because this maneuver requires a high degree of cognitive resources, advanced driver assistance systems (ADAS) and in-vehicle information systems (IVIS) have been designed to compensate for age-related weaknesses (Baldwin 2002, Gelau et al. 2011, Eby et al. 2012, Dotzauer et al. 2013). Research on this topic that examines older drivers is relatively recent, and further studies are needed to analyze healthy and cognitively impaired older drivers' use of ADAS and navigation instructions while driving. Instructions that are delivered by an invehicle navigation system (such as GPS) provide up-to-date traffic information that is designed to improve car safety and, more generally, road safety. However, in-vehicle information or guidance instructions must be precise and non-ambiguous, must be given at the appropriate time, and must lighten the cognitive load of drivers while maneuvering. Moreover, the design of these assistance and information systems must be studied in depth to be relevant both to older drivers in general and to older drivers with $A D$. In a previous study, Baldwin (2002) provided evidence of the difficulties that older drivers face when performing navigational tasks while simultaneously maintaining safe control of motor vehicles. 
Most studies of normal or neurologically impaired older adults at intersections have been based on records in accident databases (Preusser et al. 1998, Daigneault et al. 2002, Lafont et al. 2010a) or on a driving simulator applying collision avoidance paradigms (Caird and Hancock 2002, Caird et al. 2005, Uc et al. 2006, Vaux et al. 2010, Eby et al. 2012). A less documented topic is the application of an in situ experimental approach that observes and describes the driving activity of $A D$ drivers at intersections. The objective of the present study is to complement these "more ecological data" with an in-traffic driving investigation particularly focusing on left turns at intersections. The aim is also to improve knowledge of techniques used to guide older drivers during left turn negotiation and the impact of oral instructions on driving behavior. This topic is particularly interesting to study given the recent study of Eby et collaborators showing that their early-stage dementia group was significantly more likely to become lost than the control group (Eby et al. 2012) .

Each of the nine left turns observed in the current study was decomposed into a series of actions (e.g., adapting one's speed, positioning before making the left turn), and all actions were assessed. We first examined the role of age and $A D$ variables in the ability to negotiate left turn intersections. We hypothesized that older drivers would make more errors when making a left turn than younger drivers and that $A D$ drivers would make more errors than healthy older drivers. Second, we examined the role of the complexity of navigation instruction in left turn performance. The instruction was either "turn left," which corresponds to following simple navigation, or "follow a specific navigation (such as the center of town)," which represents following complex navigation following. In this more complex condition, the drivers needed to find signs indicating the precise direction to follow while simultaneously making a left turn. The hypothesis is that following complex navigations increases the cognitive load during left turn maneuvers and thus especially affects the driving performance of $A D$ and healthy older drivers. Third, from a more clinical perspective, we examined the relationship between driving performance at left turn intersections and cognitive measures to identify what types of cognitive functions or cognitive tests are more strongly related to scores on this maneuver according to age and instruction. 


\section{Method}

The experiment occurred in two phases. The first phase consisted of cognitive assessment, and the second phase consisted of an in-traffic road evaluation. The study was approved by the Ifsttar biomedical ethical committee. Informed consent was obtained in accordance with institutional guidelines to ensure the safety and confidentiality of human participants.

\subsection{Participants}

Fifty-four active drivers who drove at least 3,000 km per year and who had a valid driver's license participated in the study. These participants formed 3 groups (Table I). The first group was composed of 18 younger drivers, the second consisted of 18 healthy older individuals, and the third consisted of 18 older individuals with early-stage AD. Patients were recruited sequentially for the study if they had been diagnosed with early-stage AD based on a complete evaluation conducted by clinicians at the Bellevue Hospital Neuropsychological Center in Saint-Etienne (France). The clinical diagnosis of AD was based on the DSM-IV criteria (American Psychiatric Association 1994) and the NINCDS-ADRDA criteria (McKhann et al. 1984). All patients had a cerebral scanner without iodine and a biological checkup. The exclusion criteria were physical, neurological and ophthalmological disorders that could impair driving abilities. 
Table I: Demographic characteristics of the three groups

\begin{tabular}{lccc}
\hline & $\begin{array}{c}\text { Younger } \\
\text { drivers } \\
(n=18)\end{array}$ & $\begin{array}{c}\text { Healthy older } \\
\text { drivers } \\
(n=18)\end{array}$ & $\begin{array}{c}\text { Drivers with } \\
\text { Alzheimer's } \\
\text { disease } \\
(n=18)\end{array}$ \\
\hline Sex & & & \\
$\quad$ males/females & $12 / 6$ & $13 / 5$ & $16 / 2$ \\
Age m (sd) & $32.0(6.8)$ & $74.5(5.4)$ & $72.7(4.8)$ \\
min-max & $23-45$ & $67-83$ & $65-82$ \\
Education level & - & 7 & 5 \\
0-5 years & 7 & 7 & 7 \\
6-10 years & 4 & 4 & 6 \\
More than 10 years & & & \\
\hline
\end{tabular}

\subsection{Cognitive evaluation}

A battery of pencil-paper and computerized attentional tests was administered to all participants. The tests were chosen to reflect different components of cognitive processes that should be related to driving abilities and should potentially concern AD patients; these tests recorded both time and accuracy performance. The administered pencil-paper tests included a global cognitive function test (Mini-Mental State Evaluation, MMSE), a verbal fluency task (Isaac Set Test), a visuospatial perception and working memory test (Benton Visual Retention Test used in recognition, BVRT), a selective attention test (Zazzo's Cancellation Test, ZCT), and a visuoattentional speed test (Wechsler Digit Symbol Substitution Test, WDSST). Some attentional tests from a computerized attentional battery created by Amieva were also administered (Amieva et al. 2000). These tests included a single reaction time test; a stop signal test in which participants had to touch a target on the screen unless a sound signal was emitted after the display of a visual signal; two inhibition tests, which included a go/no-go test in which participants had to touch a specified target and not react to other targets and the Stroop test, a double task in which participants had to simultaneously perform a visual rotation task and make a semantic judgment; and a finger tapping test, in which participants had to tap a key as rapidly as possible for 60 seconds.

\subsection{The vehicle and the left turn situation}


Driving was assessed in a vehicle with a manual gearbox and dual controls. The car was equipped with four mini-video cameras that were placed in different locations to provide four views: one view of the road in front and one behind the car, the full view of the driver and a view of the driver's face. For both groups of older participants, all road tests were conducted by the same professional driving instructor (seated on the front passenger seat), who provided directions to the participants and ensured that the vehicle's safety was maintained. The driving instructor (but not the experimenter) was unaware of the clinical diagnosis of the drivers. The experimenter, who sat in the back seat, recorded driving performance in real time and used video recordings after the road test. Each subject was observed on the same route through the city center and suburbs of Saint-Etienne in daylight. The road test took approximately 45 minutes and included the most common driving situations (e.g., stop signs, traffic lights, right turns and left turns at intersections, entering and exiting an interstate highway, changing lanes, merging into traffic). For the purpose of this study, nine left turns at intersections were considered: two of these turns were protected by traffic lights, two had a stop sign, and five involved no signs. The subjects drove in moderate traffic during midmorning or mid-afternoon. Before driving the experimental route, all subjects had 20 minutes to familiarize themselves with the vehicle.

\subsection{Driving performance}

The experimenter assessed the participants' driving performance based on 10 predetermined actions that the drivers were expected to perform for each of the 9 left turns (e.g., slow down, control the mirror, use turn signals). The experimenter completed a sheet with the predetermined actions and assessed the quality of these actions and decisions (see Ranchet et al., 2013, for a comparable assessment methodology) (Ranchet et al. 2013). One point was given if the action was correct, and zero points were given if the action was not made or was inappropriate. A mean total score was calculated for each participant. A second qualitative analysis was made to categorize the actions into three types of skills: 1. planning skills included adapting one's speed (slowing down before the intersection), looking in the 
mirror to verify the traffic behind the vehicle, using turn signals before the left turn, positioning before turning left and selecting the correct line, and assessing the traffic on the road in front of the vehicle (e.g., other vehicle, pedestrians); 2. motor skills included coordinating the clutch and accelerator and applying an appropriate turning trajectory (not too wide and not cutting the corner); and 3. decision-making skills involved understanding the intentions of other drivers, stopping when a vehicle is too close on the opposite line (gap rejection), and making the left turn (e.g., satisfactory gap, good decision).

For five left turns, the navigation instructions were "at the next intersection, turn left" (simple left turns). For four intersections, the navigation instructions were "at the next intersection, follow the direction of downtown" or "follow the direction of the hospital." For these left turns (complex left turns), the drivers needed to find information in the environment by themselves; thus, the attentional demand was higher in the complex condition than in the simple condition.

\subsection{Statistical analysis}

Wilcoxon tests were used to compare the cognitive performance of healthy older drivers and younger drivers to determine the age effect and the performance of healthy older participants and $A D$ participants to determine the disease effect. A mean left turn score was calculated for the 10 predetermined actions of the 9 left turns. A two-way analysis of variance was conducted to examine the left turn scores of the participants, with left turn instructions (simple, complex) as the within-subjects factor and with the group (younger, healthy older and $A D$ patients) as the between-subjects factor. Additional ANOVAs were conducted for each separate skill type: motor, planning and decision-making skills.

Pearson correlations were used to establish which cognitive tests were correlated with the left turn scores. All older subjects were analyzed as a group $(n=36)$, and the younger group was considered separately $(n=18)$. To determine which tests were the best predictors of left turn performance according to age group and left turn complexity, four stepwise regressions were conducted: 1) older drivers with a simple left turn, 2) older drivers with a complex left 
turn, 3) younger drivers with a simple left turn, and 4) younger drivers with a complex left turn. All statistical analyses were performed using the PASW Statistics 21 software.

\section{Results}

\subsection{Cognitive performance}

The results of the cognitive tests (with separate time and accuracy measures) are presented in Table II.

Age effect. The older subjects were significantly slower than the younger subjects on all tests. However, the faster responses of younger subjects were associated with lower accuracy on the Stroop and stop signal tests. The younger participants performed significantly better than the older subjects on the BVRT, WDST, finger tapping test and Isaac Set Test.

Disease effect. The AD participants were slower than healthy volunteers in of the 5 reaction time measures. The difference between the healthy older and AD groups was significant for the Zazzo's Cancellation Test, the Stroop interference test and the double task. Compared with the healthy participants, the AD participants performed worse on the following tests: MMSE, BVRT, WDST, Isaac Set Test, the double task and the finger tapping test. Note that the performance of the AD subjects on the double task was substantially lower than that of the healthy older subjects. The difference between the two groups was close to significance for the Stroop interference test $(p=0.053)$. 
Table II: Cognitive performance of younger, healthy older and Alzheimer's drivers $(n=54)$

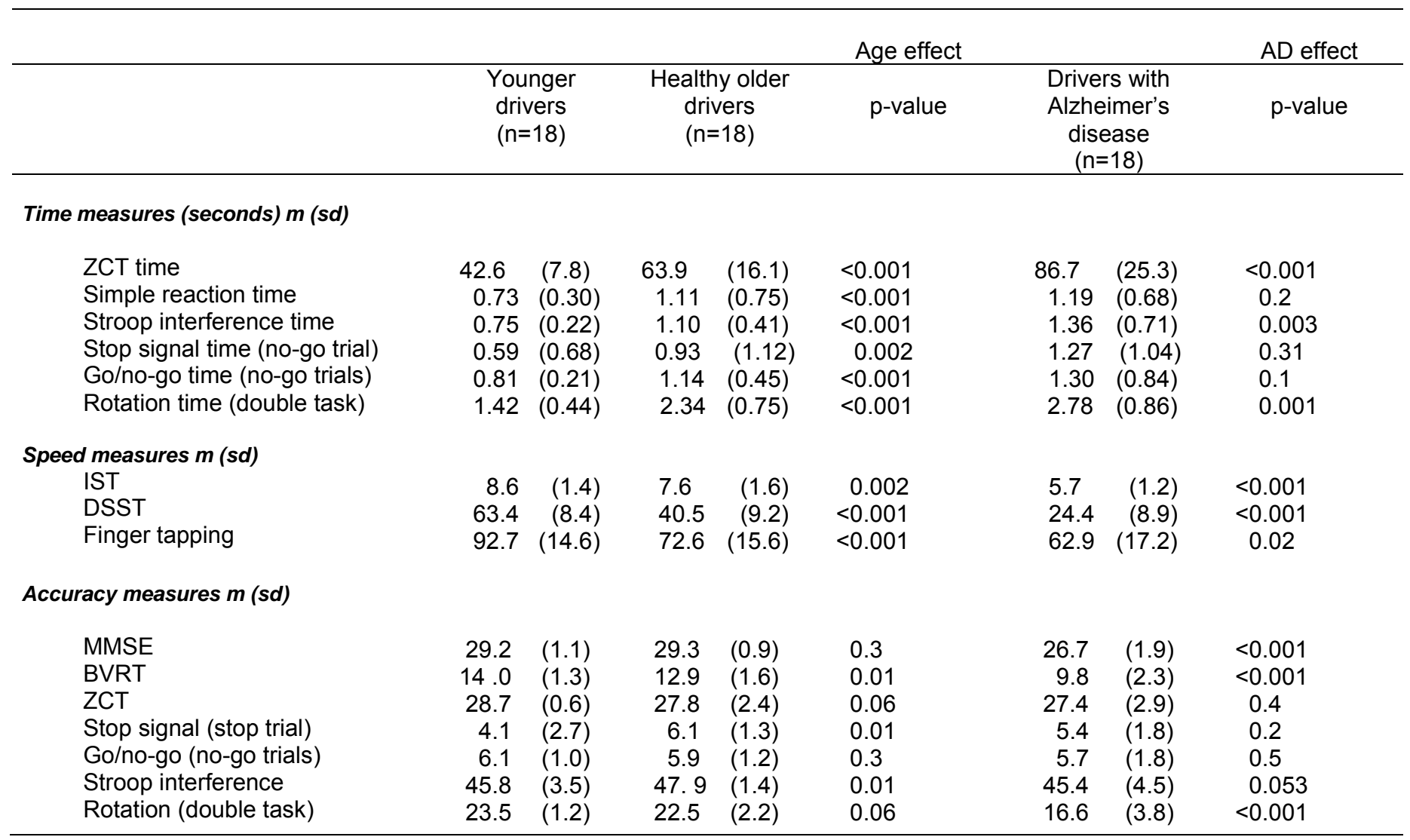

Nonparametric Wilcoxon two-sample tests

Time measures: ZCT time = time to finish the first eight lines of Zazzo's Cancellation Test; simple reaction time = time per correct response (30 trials); Stroop interference time = mean vocal time per correct response (49 stimuli); stop signal = time per correct response (22 stimuli with stop signal); go/no-go time $=$ time per correct response (22 stimuli go); and rotation time in double task = time per correct response (24 trials).

Speed measures: IST = number of correct responses given in $15 \mathrm{~s}$ on the Isaac Set Test; DDST = number of successes in $60 \mathrm{~s}$ on the Digit Symbol Substitution Test; and finger tapping = for 2 trials per hand, mean number of instances of manual pressure on a computer key in $60 \mathrm{~s}$.

Accuracy measures: MMSE = number of correct responses to Mini-Mental State Examination (30 items); BVRT $=$ number of correct responses to the Benton Visual Retention Test (15 figures); ZCT = number of correct responses $(8$ lines); stop signal = number of inhibitory responses (8 stimuli with the stop signal); go/no-go = number of correct responses (8 no-go stimuli); Stroop interference = number of correct responses (49 stimuli); and rotation in double task $=$ number of correct responses (24 trials).

\subsection{Driving evaluation}

The two-way ANOVA indicated a significant group effect, $F(2,51)=37.990, p<.000, \eta^{2}=.38$.

The left turn scores were higher in the younger group than in the AD patient group, 
$F(1,34)=69.57, \mathrm{p}<.000, \eta^{2}=.45$, and higher in the younger group than in the healthy older driver group, $F(1,34)=15.875, p<.000, \eta^{2}=.17$. However, no significant difference was recorded between the healthy older drivers and $A D$ patients, $F(1,34)=1.576, p=.214, \eta^{2}=.008$. The navigation instruction significantly affected left turn performance: the left turn scores were significantly poorer when the instruction was complex, $F(1,51)=6.322 p<.000, \eta^{2}=.18$. The interaction between the group and navigation instruction was significant, $F(2,51)=3.544$, $p=.033, \eta^{2}=.03$. As illustrated in Figure 1 , both the healthy older and AD drivers were affected by the complex instruction, $F(1,34)=5.458, p=.026, \eta^{2}=.14$ and $F(1,34)=9.740, p=.004$, $\eta^{2}=.22$, respectively, whereas the younger group was not affected, $F(1,34)=1.156, p=.290$, $\eta^{2}=.75$

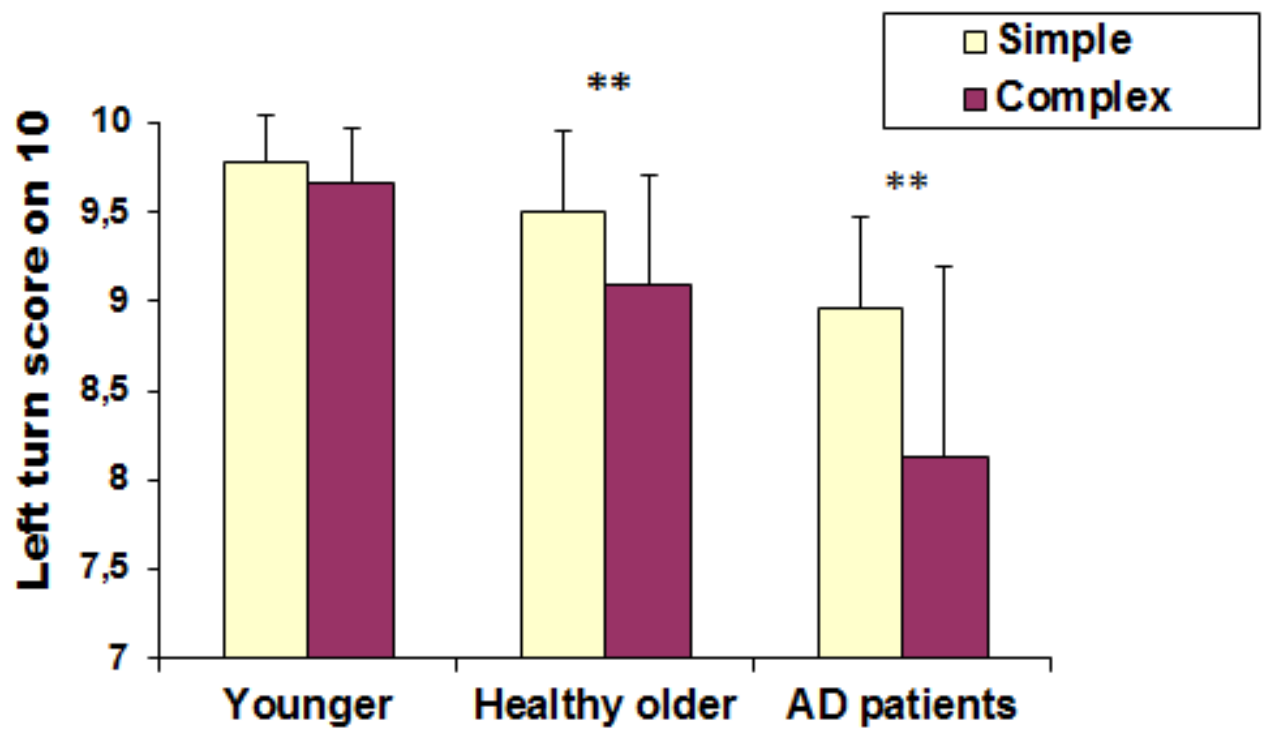

Figure 1: Driving performance according to group and left turn instruction

Performance on each of the 10 left turn actions was examined according to the three different skill types (Table III). The two-way ANOVA for psychomotor skills indicated a significant group effect, $F(2,51)=19.993, p<.000, \eta^{2}=.28$. The left turn scores were higher in the healthy older group than in the $A D$ patient group, $F(1,34)=42.439, p<.000, \eta^{2}=.37$, and 
were higher in the younger group than in the healthy older driver group, $F(1,34)=4.000$, $\mathrm{p}<.000, \mathrm{n}^{2}=.22$, and the AD patient group, $\mathrm{F}(1,34)=4.754, \mathrm{p}=.033, \eta^{2}=.064$. The results for the navigation instruction and the interaction between group and navigation instruction were not significant, $F(1,51)=.717 p=.40, \eta^{2}=.007$ and $F(1,51)=.414 p=.66, \eta^{2}=.018$, respectively. The two-way ANOVA for planning skills showed a significant group effect, $F(2,51)=7.471$, $p=.001, \eta^{2}=.12$. The left turn scores were higher in the healthy older group than in the AD patient group, $F(1,34)=15.199, p<.000, \eta^{2}=.18$, and higher in the younger group than in the AD patient group, $F(1,34)=4.088, p=.047, \eta^{2}=.055$. However, the difference between healthy older and younger drivers was not significant, $F(1,34)=2.286, p=.13, \eta^{2}=.032$. The navigation effect was significant, $F(1,51)=.041 p=.96, \eta^{2}=.001$; performance scores were higher in the simple condition than in the complex condition. The interaction between the group and navigation instruction was not significant, $F(1,51)=.041, p=.96, n^{2}=.001$.

The final ANOVA, which concerns decision-making skills, showed a significant group effect, $F(2,51)=21.002, p<.000, \eta^{2}=.26$. The left turn scores were higher in the healthy older group than in the AD patient group, $F(1,34)=22.969, p<.000, \eta^{2}=.25$, and were higher in the younger group than in the $A D$ patient group, $F(1,34)=22.969, p<.000, \eta^{2}=.25$. However, no significant difference was recorded between healthy older and younger drivers, $F(1,34)=0.0$, $p=1, \eta^{2}=.0$. The navigation instruction variable was significant, $F(1,51)=10.495, p=.002$, $\eta^{2}=.065$, with higher performance scores in the simple instruction condition than in the complex condition. Finally, the interaction between group and navigation instruction was also significant, $F(1,51)=3.471, p=.035, \eta^{2}=.018$, indicating that only $A D$ patients were significantly affected by the complex instruction (AD patients: $F(1,51)=22.969, p=<000, \eta^{2}=.25$, healthy older drivers: $F(1,51)=2.354, p=.13, \eta^{2}=.065$, and younger drivers: $F(1,51)=.246, p=.623$, $\left.\eta^{2}=.007\right)$ 
Table III: Mean percentage of correct actions (and standard deviation) according to the three different components (psychomotor, planning and decision-making skills) and the three groups (younger, healthy older and AD patients) and left turn instructions (simple vs. complex)

\begin{tabular}{lccc}
\hline & Younger & $\begin{array}{c}\text { Healthy } \\
\text { older }\end{array}$ & $\begin{array}{c}\text { AD } \\
\text { patients }\end{array}$ \\
\hline $\begin{array}{c}\text { Psychomotor } \\
\text { Simple instruction }\end{array}$ & $96(19)$ & $85(9)$ & $75(24)$ \\
Complex instruction & $97(16)$ & $79(9)$ & $70(16)$ \\
Planning & & & \\
Simple instruction & $91(11)$ & $94(7)$ & $86(8)$ \\
Complex instruction & $90(12)$ & $88(8)$ & $78(14)$ \\
Decision making & & & \\
Simple instruction & $96(7)$ & $97(4)$ & $88(10)$ \\
Complex instruction & $94(9)$ & $93(11)$ & $75(15)$ \\
\hline
\end{tabular}

\subsection{Relationship between cognitive functioning and left turn performance}

Associations between cognitive measures and both simple and complex navigation instructions at left turns were examined using Pearson's correlation. As previously observed, both the healthy older and AD groups were affected by the navigation instruction (in contrast to the younger group); thus, all older subjects were analyzed as a group ( $n=36)$, and the younger group was considered separately $(n=18)$. For the older group, simple left turns were significantly correlated with the time measure of Zazzo's Cancellation Test $(r=-0.45, p=.009)$, MMSE ( $r=0.44, p=.02)$ and DSST $(r=0.43, p=.02)$; complex left turns were correlated only with DSST $(r=0.41, p=.02)$. For the younger group, simple left turns were significantly correlated with the time measure of Stroop interference $(r=-0.48, p=.04)$ and with the MMSE $(r=0.65, p=.003)$, and complex left turns were correlated with Zazzo's Cancellation Test accuracy $(r=0.52, p=.03)$.

Only cognitive measures that were significantly associated with left turn performance were entered in the four stepwise linear regression models. For the older group, the DSST significantly predicted simple $\left(R^{2}=0.24, F=10.5, p=.003\right)$ and complex $\left(R^{2}=0.25, F=11.5\right.$, 
$p=.002)$ left turn performance. For the younger group, both the MMSE and the time measure of Stroop interference significantly predicted simple left turns $\left(R^{2}=0.58, F=10.2, p=.002\right)$, and Zazzo's Cancellation Test accuracy predicted complex left turns $\left(R^{2}=0.27, F=5.87, p=.026\right)$.

\section{Discussion}

The primary purpose of this study was to investigate the ability of younger, healthy older and $A D$ drivers to negotiate a left turn intersection. Our original approach was to examine actions involved in this maneuver in a real driving context. We first discuss the role of the navigation instruction task in left turn intersection performance. We then comment on the association between driving performance at left turn intersections and cognitive states. Finally, we discuss the DSST as the best predictor of left turn performance among older adults.

\section{Navigation task at left turn intersections}

First, the results showed poorer performance at left turn intersections among healthy older and $A D$ drivers than among younger drivers. This result confirms previous studies indicating that the predominant problem among older drivers is negotiating intersections (Staplin et al. 1997, Staplin et al. 2001). Second, we showed that the gap between older and younger drivers increased when the left turns were complex (i.e., when drivers must search for their direction while simultaneously executing the maneuver). The demand of the navigation task increased the cognitive load during the maneuver and affected the performance of both $A D$ and healthy older drivers but did not affect younger drivers. With additional complexity, such as more complex navigation instructions, the negotiation of left turns becomes more difficult for older drivers because of the increased number of information sources that must be sampled. Other authors recently showed a same adverse effect of navigation instructions. Older drivers made more errors while performing concurrent secondary navigation tasks compared to baseline driving when they were not performing secondary tasks (Aksan et al. 2015). They also specified that drivers with neurological diseases made more safety errors particularly during navigation. 
Second, a more detailed analysis that differentiated actions based on psychomotor skills, planning skills or decision-making skills provided additional interesting results. For the psychomotor skill component, we observed a group effect indicating that older drivers (healthy and $A D$ ) were more affected than younger drivers in terms of psychomotor features such as "coordinating clutch/accelerator" and "turning trajectory." The finding that older drivers expressed greater difficulties in psychomotor coordination is not surprising, as their reduced strength, flexibility and range of body motion caused by arthritis or other conditions can negatively affect driving. However, we did not observe any interaction between the group and navigation instruction variables. Thus, these psychomotor difficulties were not more apparent in situations of complex left turns when the cognitive load is greater. Therefore, this psychomotor effect is a more specific age-related effect that is independent of the cognitive component. For actions related to planning skills, we recorded both group and navigation instruction effect. The results showed that planning difficulties were specifically observed in those with $A D$, whose scores were significantly lower than the scores of younger and healthy older drivers. In general, the complex navigation instruction affected drivers' planning actions but did not have a particular effect on one group (no interaction). Interestingly, decisionmaking skills appear to be disease related, as demonstrated by the significant interaction between group and navigation instruction: indeed, AD patients were more affected by complex navigation instructions than the other two groups when performing left turns. This result is consistent with the literature indicating that $A D$ patients tend to make more random decisions and do not adapt their strategies in decision-making tasks (Delazer et al. 2007). This finding highlights the importance of carefully considering the navigation instructions when developing navigation systems. Such instruction must be correctly adapted to simplify drivers' assessment of the environment and to avoid increasing the cognitive load of older drivers. Because of this population's difficulties negotiating left turn intersections, all of their attentional resources should be oriented toward these maneuvers. The driving assistance system should reduce this cognitive load and facilitate decision making for drivers negotiating 
left turns. Advanced automotive technologies such as in-vehicle route guidance and navigational displays have the potential to improve safety and mobility if designed in accordance with the sensory/cognitive abilities of older drivers.

\section{The DSST as the best predictor of the left turn performance of older drivers}

Recently, the study of Lafont et al. (2010) showed that the WDSST was the best cognitive measure for detecting unsafe drivers. The DDST was associated with the composite indicator of unsafe driving calculated based on 3 unsafe indicators (driving score $>31$, driving instructor intervention score $>9$ and unsafe driving instructor judgment). In the present study, the DSST was associated with the driving left turn scores of older drivers in both the simple and complex left turn conditions and was found to be the best measure for predicting the left turn scores of older drivers. As noted by the authors of the cited study, the structure of the DSST is particularly composite, reflecting different processes that are involved in driving and, more specifically, driving at intersections, such as motor persistence, sustained attention, response speed and visuomotor coordination (Schear and Sato 1989). Perceptual organization components, complex scanning and visual tracking are also measured by this test (Kaufman et al. 1991). Finally, the results of the present study are consistent with those of Lafont et al.: the DSST appears to be useful for indicating potentially unsafe driving and left turn performance. These data confirm that the DSST could be utilized as a screening tool for general practitioners.

\section{Slowing down and time pressure during left turn maneuvers}

As expected and consistent with the literature, in the current study, healthy older people were cognitively slower than younger drivers, and AD participants were slower than healthy older drivers. All three speed measures (IST, DSST, and finger tapping) were affected by both age and the presence of disease. These tasks are conducted in a context of strong temporal pressure; they must be performed as rapidly as possible (both speed and accuracy are required). These instructions create conditions that are similar to those that prevail at left turn 
intersections under strong time pressure (Rizzo et al. 2001, Caird and Hancock 2002). Indeed, drivers must select relevant information; interpret roadway situations; develop a plan; assess current traffic information; and use the accelerator, brakes and steering controls appropriately. Finally, all of these actions must be performed within a short period of time because aspects of traffic can change rapidly and because a driver located in a vehicle behind the individual negotiating the intersection may be impatient.

Other studies have also highlighted the importance of the time factor for older drivers negotiating intersections. For example, in an analysis of detailed accident data, Van Eslande (2003) showed that slow decision making and action are responsible for a considerable proportion of the mistakes involving older drivers at intersections (Van Eslande 2003). In particular, research on left turn and gap acceptance decisions has revealed that older drivers (aged 70 and above) are generally slower and make more errors than younger drivers do. Likewise, Caird et al. (2005) showed that age and time are significant predictors of decision performance at left turn intersections.

Another finding for older drivers merits some discussion. The data from the stop signal and Stroop interference tests conformed to the classical speed-accuracy tradeoff described by Salthouse (1985). Although the older drivers in this study were slower than the younger drivers, they were also more accurate. We can speculate about how this speed-accuracy tradeoff applies to the driving situation and what form it takes in practice, particularly at an intersection. It would be logical that such a tradeoff may help older drivers maintain general driving skills: older drivers make relatively few driving errors that place them at severe risk and are generally not involved in more road traffic accidents (Hakamies-Blomqvist et al. 2002), but they also drive at considerably reduced speed. This form of compromise aims to guarantee both their ability to travel and their safety. It is also a form of adaptation and acceptance of their own limitations (Hakamies-Blomqvist 1994, Gabaude et al. 2010). In sum, the general slowing of older drivers can have consequences for their driving performance at left turn intersections. Slow performance at intersections can result in 
hazardous conflicts. The hesitancy and lower speeds of $A D$ and older drivers may confuse other drivers at intersections (Hakamies-Blomqvist, 1994) and may result in dangerous situations. However, this slowing can also be considered as a form of regulation to maintain driving activity and autonomy. The question remains as to how can we help older drivers and reduce difficulties for them. We can hypothesize that older drivers can make good use of driving assistance systems, particularly those that are developed to reduce left turn conflicts at intersections. Dotzauer et al. (2013) recently showed that an intersection assistant facilitates changes in both the driving performance and driving behaviors of older drivers. Driving with ADAS in a simulator tended to improve intersection crossing, as intersections were crossed with higher speeds and smaller risk, indicating a reduced time to contact (TTC). Further studies are needed to determine what type of processes should be prioritized to reduce the difficulties and risks for older drivers at left turn intersections (e.g., select information, prepare actions, and estimate the speed of vehicles driving in the other direction, make decisions). Regardless of the process selected, it must be considered that older drivers require more time to react, to prepare action, and to make decisions; thus, the time variable is crucial. Instructions should be given in a manner that enables older drivers to have sufficient time to process information and adapt their behavior.

\section{Conclusion}

We have shown that navigation instruction has a crucial influence on negotiating left turns among older drivers, whereas younger drivers are not affected by directional instructions. From a practical perspective, the present results have also demonstrated the importance of considering that older drivers are particularly sensitive to time pressure in complex situations such as left turn intersections. Road design should account for this information because the number of older drivers, whether they are healthy or have a neurological disease, will increase in the coming decades. In the future, it will be necessary to reduce the complexity of intersections to facilitate consideration of all presented information. The question remains as 
to whether roundabouts are safer than left turns or other types of intersections for older drivers.

Additionally, these findings have emphasized that greater attention should be accorded to instruction in the developing navigation systems. Such instruction must be adapted to avoid increasing the cognitive load of $A D$ patients and to help those who are more likely to become lost (Eby et al. 2012).

Concerning driving assistance systems, two questions remain unanswered. First, are Alzheimer's patients able to take advantage of such assistance systems? There is no clear answer in the literature, but research indicates that possibilities for learning and relearning are reduced for those with this pathology. Second, what operations are prioritized at left turn intersections? The results of this study indicate that older adults should receive assistance at the levels of psychomotor, planning and decision-making skills.

Of course, all the results should be carefully considered in view of the sample size and the bias of the experimental conditions: during the driving evaluation, all drivers drove one vehicle that was not their personal vehicle. We know that it is difficult for older drivers to change their habits in using a new car. Further studies are needed to complement these data.

Acknowledgements: The authors would like to thank Stephanie Dirson and Judith Kerleroux for the cognitive evaluation. We would also like to thank DSCR (Direction de la Sécurite et de la Circulation Routière), which supported this study. 


\section{References}

Aksan, N., Anderson, S.W., Dawson, J., Uc, E., Rizzo, M., 2015. Cognitive functioning differentially predicts different dimensions of older drivers' on-road safety. Accident Analysis \& Prevention 75 (0), 236-244.

American Psychiatric Association, A., 1994. Diagnostic and statistical manual of mental disorders APA, Washington.

Amieva, H., Rouch-Leroyer, I., Fabrigoule, C., Dartigues, J.F., 2000.

Deterioration of controlled processes in the preclinical phase of dementia: A confirmatory analysis. Dementia and geriatric cognitive disorders 11 (1), 4652.

Baldwin, C., 2002. Designing in-vehicle technologies for older drivers: Application of

sensory-cognitive interaction theory. Theor.issues in ergon sci. 3 (4), 307-329.

Bieliauskas, L.A., Roper, B.R., Trobe, J., Lacy, M., 1998. Cognitive measures, driving safety, and alzheimer's disease. The Clinical Neuropsychologist 12 (2), 206-212.

Braitman, K.A., Kirley, B.B., Ferguson, S., Chaudhary, N.K., 2007. Factors leading to older drivers' intersection crashes. Traffic Inj Prev 8 (2), 267-274.

Caird, J.K., Edwards, C.J., Creaser, J.I., Horrey, W.J., 2005. Older drivers failures of attention at intersections: Using change blindness methods to assess turn decision accuracy. Human Factors 47 (2), 235-249.

Caird, J.K., Hancock, P.A., 2002. Left turn and gap acceptance accidents. In: (Eds), R.E.D.R.O. ed. Human factors in traffic safety. Lawyers \& Judges, Tucson, pp. 591-640.

Chandraratna, S., Stamatiadis, N., 2003. Problem driving maneuvers of elderly drivers. Transportation Research Record 1843 89-95.

Charlton, J., 2006. Influence of chronic illness on crash involvement of motor vehicle occupants. In: 213, R.N. ed. Monash University Accident Research Centre, Melbourne, Australia

Clarke, D.D., Ward, P., Bartle, C., Truman, W., 2010. Older drivers' road traffic crashes in the uk. Accident Analysis \& Prevention 42 (4), 1018-1024.

Cooper, P.J., 1990. Differences in accident characteristics among elderly drivers and between elderly and middle-aged drivers. Accident Analysis and Prevention 22 (5), 499-508.

Daigneault, G., Joly, P., Frigon, J.Y., 2002. Previous convictions or accidents and the risk of subsequent accidents of older drivers. Accident Analysis \& Prevention 34 (2), 257-261.

Delazer, M., Sinz, H., Zamarian, L., Benke, T., 2007. Decision-making with explicit and stable rules in mild alzheimer's disease. Neuropsychologia 45 (8), 1632-1641.

Dotzauer, M., Caljouw, S.R., De Waard, D., Brouwer, W.H., 2013. Intersection assistance: A safe solution for older drivers? Accident Analysis \& Prevention $59(0), 522-528$.

Drachman, D.A., Swearer, J.M., 1993. Driving and alzheimer's disease: The risk of crashes. Neurology 43 (12), 2448-56.

Dubinsky, R.M., Stein, A.C., 2002. Practice parameter : Risk of driving and alzheimer's disease (reply). Neurology 56, 695.

Dubinsky, R.M., Stein, A.C., Lyons, K., 2000. Practice parameter: Risk of driving and alzheimer's disease (an evidence-based review): Report of the quality 
standards subcommittee of the american academy of neurology. Neurology 54 (12), 2205-2211.

Duchek, J.M., Carr, D.B., Hunt, L., Roe, C.M., Xiong, C., Shah, K., Morris, J.C., 2003. Longitudinal driving performance in early-stage dementia of the alzheimer type. Journal of American Geriatrics Society 51 (10), 1342-1347.

Duchek, J.M., Hunt, L., Ball, K., Buckles, V., Morris, J.C., 1997. The role of selective attention in driving and dementia of the alzheimer type. Alzheimer Disease and Associated Disorders 11 Suppl 1, 48-56.

Duchek, J.M., Hunt, L., Ball, K., Buckles, V., Morris, J.C., 1998. Attention and driving performance in alzheimer's disease. Journal of Gerontology 53 (2), P130-41.

Dukic, T., Broberg, T., 2012. Older drivers' visual search behaviour at intersections. Transportation Research Part F: Traffic Psychology and Behaviour 15 (4), 462-470.

Eby, D.W., Silverstein, N.M., Molnar, L.J., Leblanc, D., Adler, G., 2012. Driving behaviors in early stage dementia: A study using in-vehicle technology Accident Analysis \& Prevention 49, 330-337.

Friedland, R.P., Koss, E., Kumar, A., Gaine, S., Metzler, D., Haxby, J.V., Moore, A., 1988. Motor vehicle crashes in dementia of the alzheimer type. Annals of Neurology 24 (6), 782-6.

Gabaude, C., Marquié, J.-C., Obriot-Claudel, F., 2010. Self-regulatory driving behaviour in the elderly: Relationships with aberrant driving behaviours and perceived abilities. Le travail Humain 73 (1), 31-73.

Gelau, C., Sirek, J., Dahmen-Zimmer, K., 2011. Effects of time pressure on leftturn decisions of elderly drivers in a fixed-base driving simulator.

Transportation Research Part F: Traffic Psychology and Behaviour 14 (1), 76 86.

Grace, J., Amick, M.M., D'abreu, A., Festa, E.K., Heindel, W.C., Ott, B.R., 2005. Neuropsychological deficits associated with driving performance in parkinson's disease and alzheimer's disease. Journal of the International Neuropsychological Society 11, 766-775.

Hakamies-Blomqvist, L., 1994. Compensation in older drivers as reflected in their fatal accidents. Accident Analysis and Prevention 26 (1), 107-112.

Hakamies-Blomqvist, L., Raitanen, T., O'neill, D., 2002. Driver ageing does not cause higher accident rates per km. Transportation Research Part F: Traffic Psychology and Behaviour 5 (4), 271-274.

Kaufman, A.S., Mclean, J.E., Reynolds, C.R., 1991. Analisis of wais-r patterns by sex and race. Journal of Clinical Psychology 47 (4), 548-557.

Lafont, S., Gabaude, C., Paire-Ficout, L., Fabrigoule, C., 2010a. Les conducteurs âgés sont moins dangereux pour les autres usagers dans toutes les situations de conduite : Étude des accidents corporels en france entre 1996 et 2006. Le travail Humain 73 (1), 74-93.

Lafont, S., Marin-Lamellet, C., Paire-Ficout, L., Thomas-Anterion, C., Bernard, L., Fabrigoule, C., 2010b. The wechsler digit symbol substitution test as the best predictor of unsafe driving in alzheimer disease and normal aging. Dementia and Geriatric Cognitive Disorders 29, 154-163.

Mayhew, D.R., Simpson, H.M., Ferguson, S.A., 2006. Collisions involving seniordrivers: High-risk conditions and locations. Traffic Injury Prevention 7 (2), 117-124. 
Mckhann, G., Drachman, D.A., Folstein, M., Katzman, R., Price, D., Stadlan, E., 1984. Clinical diagnosis of alzheimer's disease: Report of the nincds-adrda work under suspices of the department of health and human services task force in alzheimer's disease. Neurology 34, 939-945.

Oxley, J., Fildes, B., Corben, B., Langford, J., 2006. Intersection design for older drivers. Transportation Research Part F: Traffic Psychology and Behaviour 9 (5), 335-346.

Perry, R.J., Hodges, J.R., 1999. Attention and executive deficits in alzheimer's disease. A critical review. Brain 122 ( Pt 3), 383-404.

Preusser, D.F., Williams, A.F., Ferguson, S.A., Ulmer, R.G., Weinstein, H.B., 1998. Fatal crash risk for older drivers at intersections. Accident Analysis \& Prevention 30 (2), 151-9.

Ranchet, M., Paire-Ficout, L., Uc, E.U., Bonnard, A., Sornette, D., Brousolle, E., 2013. Impact of specific executive functions on driving performance in people with parkinson's disease. Movement Disorders.

Rizzo, M., Mcgehee, D.V., Dawson, J.D., Anderson, S.N., 2001. Simulated car crashes at intersections in drivers with alzheimer disease. Alzheimer Disease and Associated Disorders 15 (1), 10-20.

Schear, J.M., Sato, S.D., 1989. Effects of visual acuity and visual motor speed and dexterity on cognitive test performance. Archives of Clinical Neuropsychology 4 (1), 25-32.

Staplin, L., Harkey, D.L., Lococo, K.H., Tarawneh, M.S., 1997. Intersection gemetric design and operational guidelines for older drivers and pedestrians. pp. i-17.

Staplin, L., Lococo, K., S., B., D. Harkey, 2001. Highway design handbook for older drivers and pedestrians (report no. Fhwa-rd-01-103). In: Federal Highway Administration, U.D.O.T. ed., Washington DC, USA

Storandt, M., Beaudreau, S., 2004. Do reaction time measures enhance diagnosis of early-stage dementia of the alzheimer type. Archives of Clinical Neuropsychology 19 (1), 119-124.

Sylvain-Roy, S., Bherer, L., Belleville, S., 2010. Contribution of temporal preparation and processing speed to simple reaction time in persons with alzheimer's disease and mild cognitive impairment. Brain and Cognition 74 (3), 255-261.

Szlyk, J., Myers, L., Zhang, Y., Wetzel, L., Shapiro, R., 2002. Development and assement of a neuropsychological battery to aid in predicting performance. Journal of Rehabilitation Research Development 39 (4), 483-496.

Tales, A., Muir, J.L., Bayer, A., Snowden, R.J., 2002. Spatial shifts in visual attention in normal ageing and dementia of the alzheimer type. Neuropsychologia 40 (12), 2000-12.

Tales, A., Muir, J.L., Jones, R., Bayer, A., Snowden, R.J., 2004. The effects of saliency and task difficulty on visual search performance in ageing and alzheimer's disease. Neuropsychologia 42 (3), 335-345.

Tuokko, H., Tallman, K., Beattie, B.L., Cooper, P., Weir, J., 1995. An examination of driving records in a dementia clinic. Journal of Gerontology 50 (3), S173-81.

Uc, E., Rizzo, M., Anderson, S.N., Shi, Q., Dawson, J.D., 2005. Driver landmark and traffic sign identification in early alzheimer's disease. Journal of Neurology, Neurosurgery and Psychiatry 76, 764-768. 
Uc, E., Rizzo, M., Anderson, S.W., Shi, Q., Dawson, J.D., 2004. Driver routefollowing and safety errors in early alzheimer disease. Neurology 63 (832837).

Uc, E., Rizzo, M., Anderson, S.W., Shi, Q., Dawson, J.D., 2006. Unsafe rear-end collision avoidance in alzheimer's disease. Journal of the Neurological Sciences 251 (1-2), 35-43.

Van Eslande, P., 2003. Elderly drivers errors. Recherche Transports Sécurité 81, 190-202.

Vaux, L.M., Ni, R., Rizzo, M., Uc, E.Y., Andersen, G.J., 2010. Detection of imminent collisions by drivers with alzheimer's disease and parkinson's disease: A preliminary study. Accident Analysis \& Prevention 42 (3), 852-858.

Whelihan, W.M., Dicarlo, M.A., Paul, R.H., 2005. The relationship of neuropsychological functioning to driving competence in older persons with early cognitive decline. Archives of Clinical Neuropsychology 20 (2), 217-228. 


\section{Legend}

Table I: Demographic characteristics of the three groups

Table II: Cognitive performances of younger, healthy older and Alzheimer's drivers $(n=54)$

Figure 1: Driving performance according to group and left turn instruction $(n=54)$

Table III: Mean percentage of correct actions (and standard deviation) according to the three different components (psychomotor, planning and decision-making skills) and the three groups (younger, healthy older and AD patients) and left turn instructions (simple vs. complex) 
Table I: Demographic characteristics of the three groups

\begin{tabular}{lccc}
\hline & $\begin{array}{c}\text { Younger } \\
\text { drivers } \\
(\mathrm{n}=18)\end{array}$ & $\begin{array}{c}\text { Healthy older } \\
\text { drivers } \\
(\mathrm{n}=18)\end{array}$ & $\begin{array}{c}\text { Drivers with } \\
\text { Alzheimer's } \\
\text { disease } \\
(\mathrm{n}=18)\end{array}$ \\
\hline $\begin{array}{l}\text { Sex } \\
\text { males/females }\end{array}$ & $12 / 6$ & $13 / 5$ & \\
$\begin{array}{l}\text { Age m (sd) } \\
\text { min-max }\end{array}$ & $32.0(6.8)$ & $74.5(5.4)$ & $72.7(4.8)$ \\
Education level & $23-45$ & $67-83$ & $65-82$ \\
0-5 years & & & 5 \\
6-10 years & - & 7 & 7 \\
More than 10 years & 7 & 7 & 6 \\
& 4 & & \\
\hline
\end{tabular}


Table II: Cognitive performance of younger, healthy older and Alzheimer's drivers $(n=54)$

\begin{tabular}{|c|c|c|c|c|c|c|c|c|}
\hline & & & \multirow{2}{*}{\multicolumn{2}{|c|}{$\begin{array}{l}\text { Healthy older } \\
\text { drivers } \\
(n=18)\end{array}$}} & \multirow{2}{*}{$\begin{array}{r}\text { Age effec } \\
\text { p-value }\end{array}$} & \multirow{2}{*}{\multicolumn{2}{|c|}{$\begin{array}{c}\text { Drivers with } \\
\text { Alzheimer's } \\
\text { disease } \\
(n=18)\end{array}$}} & \multirow{2}{*}{$\frac{\text { AD effect }}{\text { p-value }}$} \\
\hline & \multicolumn{2}{|c|}{$\begin{array}{l}\text { Younger } \\
\text { drivers } \\
(n=18)\end{array}$} & & & & & & \\
\hline $\begin{array}{l}\text { ZCT time } \\
\text { Simple reaction time } \\
\text { Stroop interference time } \\
\text { Stop signal time (no-go trial) } \\
\text { Go/no-go time (no-go trials) } \\
\text { Rotation time (double task) }\end{array}$ & $\begin{array}{r}42.6 \\
0.73 \\
0.75 \\
0.59 \\
0.81 \\
1.42\end{array}$ & $\begin{array}{l}(7.8) \\
(0.30) \\
(0.22) \\
(0.68) \\
(0.21) \\
(0.44)\end{array}$ & $\begin{array}{c}63.9 \\
1.11 \\
1.10 \\
0.93 \\
1.14 \\
2.34\end{array}$ & $\begin{array}{l}(16.1) \\
(0.75) \\
(0.41) \\
(1.12) \\
(0.45) \\
(0.75)\end{array}$ & $\begin{array}{r}<0.001 \\
<0.001 \\
<0.001 \\
0.002 \\
<0.001 \\
<0.001\end{array}$ & $\begin{array}{c}86.7 \\
1.19 \\
1.36 \\
1.27 \\
1.30 \\
2.78\end{array}$ & $\begin{array}{l}(25.3) \\
(0.68) \\
(0.71) \\
(1.04) \\
(0.84) \\
(0.86)\end{array}$ & $\begin{array}{l}<0.001 \\
0.2 \\
0.003 \\
0.31 \\
0.1 \\
0.001\end{array}$ \\
\hline $\begin{array}{l}\text { Speed measures } \boldsymbol{m}(\mathbf{s d}) \\
\text { IST } \\
\text { DSST } \\
\text { Finger tapping }\end{array}$ & $\begin{array}{r}8.6 \\
63.4 \\
92.7\end{array}$ & $\begin{array}{r}(1.4) \\
(8.4) \\
(14.6)\end{array}$ & $\begin{array}{l}7.6 \\
40.5 \\
72.6\end{array}$ & $\begin{array}{r}(1.6) \\
(9.2) \\
(15.6)\end{array}$ & $\begin{array}{r}0.002 \\
<0.001 \\
<0.001\end{array}$ & $\begin{array}{l}5.7 \\
24.4 \\
62.9\end{array}$ & $\begin{array}{r}(1.2) \\
(8.9) \\
(17.2)\end{array}$ & $\begin{array}{c}<0.001 \\
<0.001 \\
0.02\end{array}$ \\
\hline $\begin{array}{l}\text { Accuracy measures } \boldsymbol{m} \text { (sd) } \\
\qquad \begin{array}{l}\text { MMSE } \\
\text { BVRT } \\
\text { ZCT } \\
\text { Stop signal (stop trial) } \\
\text { Go/no-go (no-go trials) } \\
\text { Stroop interference } \\
\text { Rotation (double task) }\end{array}\end{array}$ & $\begin{array}{r}29.2 \\
14.0 \\
28.7 \\
4.1 \\
6.1 \\
45.8 \\
23.5\end{array}$ & $\begin{array}{l}(1.1) \\
(1.3) \\
(0.6) \\
(2.7) \\
(1.0) \\
(3.5) \\
(1.2)\end{array}$ & $\begin{array}{c}29.3 \\
12.9 \\
27.8 \\
6.1 \\
5.9 \\
47.9 \\
22.5\end{array}$ & $\begin{array}{l}(0.9) \\
(1.6) \\
(2.4) \\
(1.3) \\
(1.2) \\
(1.4) \\
(2.2)\end{array}$ & $\begin{array}{l}0.3 \\
0.01 \\
0.06 \\
0.01 \\
0.3 \\
0.01 \\
0.06\end{array}$ & \begin{tabular}{r|}
26.7 \\
9.8 \\
27.4 \\
5.4 \\
5.7 \\
45.4 \\
16.6
\end{tabular} & $\begin{array}{l}(1.9) \\
(2.3) \\
(2.9) \\
(1.8) \\
(1.8) \\
(4.5) \\
(3.8)\end{array}$ & $\begin{array}{c}<0.001 \\
<0.001 \\
0.4 \\
0.2 \\
0.5 \\
0.053 \\
<0.001\end{array}$ \\
\hline
\end{tabular}

Nonparametric Wilcoxon two-sample tests

Time measures: ZCT time = time to finish the first eight lines of Zazzo's Cancellation Test; simple reaction time = time per correct response (30 trials); Stroop interference time = mean vocal time per correct response (49 stimuli); stop signal = time per correct response (22 stimuli with stop signal); go/no-go time $=$ time per correct response (22 stimuli go); and rotation time in double task = time per correct response (24 trials).

Speed measures: IST = number of correct responses given in $15 \mathrm{~s}$ on the Isaac Set Test; DDST = number of successes in $60 \mathrm{~s}$ on the Digit Symbol Substitution Test; and finger tapping = for 2 trials per hand, mean number of instances of manual pressure on a computer key in $60 \mathrm{~s}$.

Accuracy measures: MMSE = number of correct responses to Mini-Mental State Examination (30 items); BVRT $=$ number of correct responses to the Benton Visual Retention Test (15 figures); ZCT = number of correct responses $(8$ lines); stop signal = number of inhibitory responses (8 stimuli with the stop signal); go/no-go = number of correct responses (8 no-go stimuli); Stroop interference = number of correct responses (49 stimuli); and rotation in double task $=$ number of correct responses $(24$ trials). 


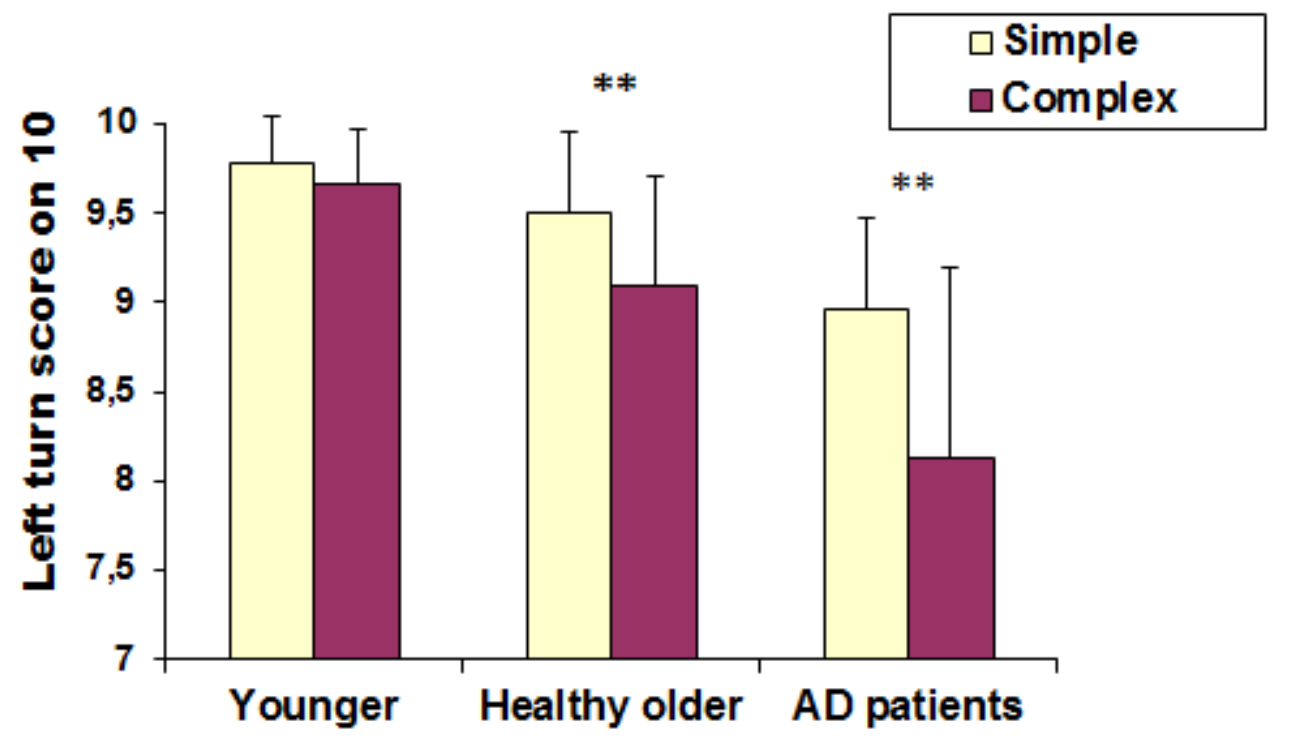

Figure 1: Driving performance according to group and left turn instruction 
Table III: Mean percentage of correct actions (and standard deviation) according to the three different components (psychomotor, planning and decision-making skills) and the three groups (younger, healthy older and $A D$ patients) and left turn instructions (simple vs. complex)

\begin{tabular}{lccc}
\hline & Younger & $\begin{array}{c}\text { Healthy } \\
\text { older }\end{array}$ & $\begin{array}{c}\text { AD } \\
\text { patients }\end{array}$ \\
\hline $\begin{array}{l}\text { Psychomotor } \\
\text { Simple instruction }\end{array}$ & $96(19)$ & $85(9)$ & $75(24)$ \\
Complex instruction & $97(16)$ & $79(9)$ & $70(16)$ \\
Planning & & & \\
Simple instruction & $91(11)$ & $94(7)$ & $86(8)$ \\
Complex instruction & $90(12)$ & $88(8)$ & $78(14)$ \\
Decision making & & & \\
$\quad$ Simple instruction & $96(7)$ & $97(4)$ & $88(10)$ \\
Complex instruction & $94(9)$ & $93(11)$ & $75(15)$ \\
\hline
\end{tabular}

